\title{
Development and Evaluation of the Supportive Needs Assessment Tool for Cirrhosis (SNAC)
}

This article was published in the following Dove Press journal:

Patient Preference and Adherence

\author{
Patricia C Valery iD $^{1,2}$ \\ Christina M Bernardes (D) \\ Katherine A Stuart ${ }^{3}$ \\ Gunter F Hartel (iD) \\ Steven M McPhail (iD ${ }^{4}$ \\ Richard Skoien ${ }^{5}$ \\ Tony Rahman ${ }^{6}$ \\ Paul J Clark ${ }^{7}$ \\ Leigh $\cup$ Horsfall ${ }^{2,3}$ \\ Kelly L Hayward (D) ${ }^{2}$ \\ Rohit Gupta ${ }^{8}$ \\ Elizabeth E Powell ${ }^{2,3}$ \\ 'QIMR Berghofer Medical Research \\ Institute, Herston, QLD, Australia; \\ ${ }^{2}$ Centre for Liver Disease Research, \\ Translational Research Institute, Faculty \\ of Medicine, The University of \\ Queensland, Brisbane, QLD, Australia; \\ ${ }^{3}$ Department of Gastroenterology and \\ Hepatology, Princess Alexandra Hospital, \\ Brisbane, QLD, Australia; ${ }^{4}$ Centre for \\ Functioning and Health Research, \\ Queensland Health and the School of \\ Public Health and Institute of Health and \\ Biomedical Innovation, Queensland \\ University of Technology, Brisbane, QLD, \\ Australia; ${ }^{5}$ Department of \\ Gastroenterology, Royal Brisbane and \\ Women's Hospital, Brisbane, QLD, \\ Australia; ${ }^{6}$ Gastroenterology \& \\ Hepatology Department, The Prince \\ Charles Hospital, Chermside, QLD, \\ Australia; ${ }^{7}$ Department of \\ Gastroenterology and Hepatology, Mater \\ Hospitals, Brisbane, QLD, Australia; \\ ${ }^{8}$ Department of Gastroenterology and \\ Hepatology, Sunshine Coast University \\ Hospital, Birtinya, QLD, Australia
}

Correspondence: Patricia C Valery QIMR Berghofer Medical Research Institute, 300 Herston Road, Herston, QLD 4006, Australia

Tel +6I 733620376

Email Patricia.Valery@qimrberghofer.edu.au
Background: We report the development and psychometric testing of a Supportive Needs Assessment tool for Cirrhosis (SNAC).

Methods: The 50-item SNAC was administered to patients $(\mathrm{n}=465)$ diagnosed with cirrhosis recruited from five metropolitan hospitals in Queensland, Australia. Items were assessed for ceiling and floor effects, and exploratory factor analysis was used to assess the factor structure. Identified factors were assessed for internal consistency and convergent validity to validated psychosocial tools.

Results: Exploratory factor analysis identified 4 factors (39 items), which together accounted for $49.2 \%$ of the total variance. The 39 -item SNAC met the requirements of a needs assessment tool and identified a range of needs important to patients with cirrhosis that were grouped in four subscales: "Psychosocial issues", "Practical and physical needs", "Information needs", and "Lifestyle changes". Cronbach's alpha values for the four subscales ranged from 0.64 to 0.92 . Convergent validity was supported by a strong correlation between the total SNAC score and that of the Chronic Liver Disease Questionnaire (CLDQ; Spearman rho $-0.68 ; \mathrm{p}<0.001$ ), and moderate correlations with the Distress Thermometer (Spearman rho $0.53 ; \mathrm{p}<0.001$ ) and seven subscales of a generic health-related quality of life instrument (Short Form 36; Spearman rho ranged from -0.48 to $-0.57 ; \mathrm{p}<0.001$ ). The SNAC discriminated patient groups with respect to sex $(\mathrm{p}=0.013)$, age group $(\mathrm{p}<0.001)$, and hospital admission status (admitted vs not; $\mathrm{p}<0.001$ ).

Conclusion: These data provide initial evidence for the validity and reliability of the SNAC, an instrument designed to measure type and amount of perceived unmet practical and psychological needs of people diagnosed with cirrhosis.

Keywords: chronic liver disease, perceived needs, instrument validation, psychometric properties

\section{Background}

Cirrhosis, the advanced stage of many chronic liver diseases, is a significant cause of liver-related morbidity ${ }^{1,2}$ and mortality ${ }^{3}$ globally. ${ }^{4-8}$ Life expectancy with early ("compensated") cirrhosis is estimated to be 12 years. ${ }^{9}$ Once liver function deteriorates ("decompensated" cirrhosis), ${ }^{5}$ patients experience multiple complications, ${ }^{1,10}$ and have a life expectancy of 2 years. ${ }^{9}$ Optimal cirrhosis care is complex and imposes a substantial burden upon patients and their caregivers. People with decompensated cirrhosis are frequently prescribed numerous medications, dietary and lifestyle modifications, and may require multiple hospital admissions to manage complications of progressive disease. The complex clinical management of advanced liver disease in addition to the functional impact of cirrhosis on activities of daily living and quality of life may result in patients with unmet practical and psychological needs. ${ }^{11-13}$ 
In this study, we refer to the term "supportive needs" as encompassing patients' perceived needs for management of symptoms, general physical and psychological health, spiritual, practical, physical, social, sexual, information, and cultural needs. ${ }^{11,14}$

Many patient-reported outcome measurements have been developed to evaluate specific areas and levels of need to guide patient care in the area of chronic diseases. For example, there are several disease-specific patient-reported measurements that assess needs in neurological conditions ${ }^{15,16}$ and cancer care. ${ }^{17,18}$ Current cirrhosis-specific patientreported measurements assess health-related quality of life (eg, CLDQ,${ }^{19}$ LC-PROM $^{20}$ ) and generic screening tools such as the Supportive and Palliative Care Indicator Tool $(\text { SPICT })^{21}$ have been used for people with advanced liver disease; however, no instrument had been designed to assess supportive needs among patients with cirrhosis. While the CLDQ $^{19}$ and LC-PROM ${ }^{20}$ include assessment of patients' symptoms, they do not consider patients' perceptions of their need for supportive care. In 2015, a review ${ }^{13}$ on unmet needs of people diagnosed with chronic liver disease worldwide highlighted a shortage of information about the needs of patients with cirrhosis. Most studies only included patients with hepatitis $\mathrm{C}$ virus infection, and 3 studies included patients with cirrhosis. Eleven of the 26 studies identified in that review reported a need for help with information about disease or disease management. In 2018, a subsequent review on supportive and palliative care in people with cirrhosis identified further eight studies (seven qualitative, one quantitative), specifically focusing on supportive needs. ${ }^{11}$ Patients and carers reported limited understanding of cirrhosis and wanted more information about their disease and its treatment, in addition to assistance with psychological and practical needs. ${ }^{11}$ The quantitative study, conducted in Australia, ${ }^{12}$ reported that patients with cirrhosis have a wide range of unmet needs due to symptoms, complications and treatment of the disease.

Accurate assessment of the supportive needs of individuals with cirrhosis is important to improve patient care. To address the lack of a specific health needs assessment instrument for this patient group for whom care is usually complex and patients are likely to have unmet needs, we developed what is, to the best of our knowledge, the first supportive needs assessment tool for cirrhosis. This article describes the development and psychometric testing of the Supportive Needs Assessment tool for Cirrhosis (SNAC).

\section{Methods}

The SNAC was developed in three stages, namely: (i) item generation; (ii) pre-testing of the first draft of the SNAC (face and content validity, review, and field-testing of the instrument); and (iii) psychometric evaluation of the newly developed SNAC (Figure 1).

\section{Patient and Public Involvement}

The public was not involved in the design or conduct of the current study. Patients with cirrhosis were involved in the study as interviewees. Findings of this study will be open to the public.

\section{Item Generation}

Informed by the findings of a systematic literature review ${ }^{13}$ and a cross-sectional study, ${ }^{12}$ the first version of the SNAC with 51 items was constructed. The review ${ }^{13}$

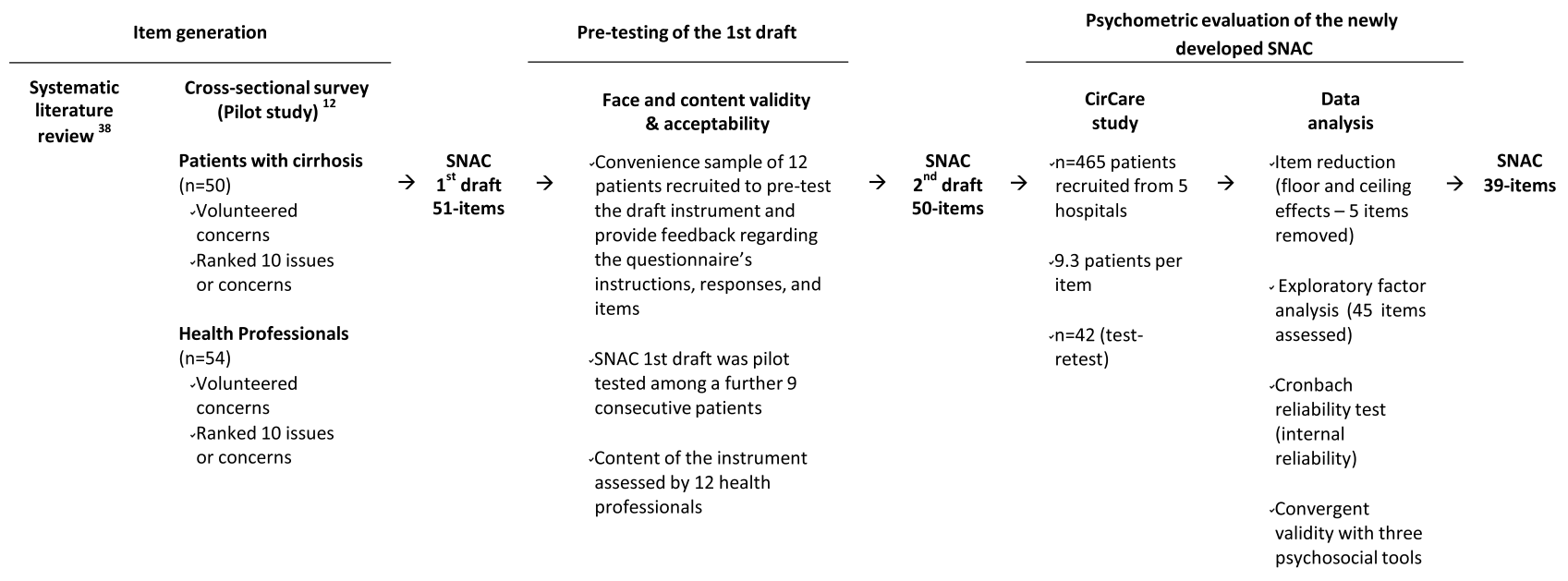

Figure I Overview of the stages of development of the Supportive Needs Assessment tool for Cirrhosis (SNAC). 
identified the supportive needs of people who had been diagnosed with chronic liver disease (CLD) and the specific items of need most frequently reported as unmet by CLD patients. The cross-sectional study conducted at a tertiary liver centre explored the concerns and challenges of patients with cirrhosis $(n=50)$ and described health professionals' perspectives $(n=54)$ of patients' needs. The results of this study have been described elsewhere. ${ }^{12}$ In brief, health professionals (nurses, physicians, psychologists and social workers) involved in caring for patients with cirrhosis identified, from their own perspectives, the principal concerns or unmet supportive needs of patients with cirrhosis. Through a structured interview conducted with patients with cirrhosis, we further identified patients' own concerns. ${ }^{12}$

SNAC responses to each item were broken down to a "yes" or "no" initial response to the opening question ("In the past month, did you ..."), followed by a Likert scale with 4 possible answers ("None", "A little", "Some", and "A lot") to the subsequent question ("How much additional help did/do you need?”). Questions were assembled into 4 sections, namely: day-to-day activities, symptoms and managing liver disease, how have patients been feeling, and information. For items $1-42$, participants were asked to answer "yes" or "no" to the opening question, and, if their answer was yes, select the answer which best described how much additional help they needed. For items 44-50, participants were asked to answer "yes" or "no" to the opening question, followed by selecting the response which best described how much additional help they needed irrespective of their answer to the opening question. This structure was chosen as it was found to be simpler and more easily understood among the underserved and minority patients who are overrepresented among the cirrhosis population. ${ }^{22}$

\section{Pre-Testing of the First Draft of the SNAC (5 I Items)}

To assess the content validity, each item was first reviewed by an expert team consisting of 5 hepatologists, 1 hepatologist-in-training, 1 liver nurse, 2 registered nurses, 1 pharmacist, and 2 scientists who have worked with patients with cirrhosis. A convenience sample of 12 patients with a diagnosis of cirrhosis was recruited from Hepatology/ Gastroenterology clinics at the Prince Charles Hospital to pre-test the draft instrument and assess its face validity and acceptability. A hepatologist-in-training ( $R G$ ) assessed patients' eligibility, obtained written consent to participate in the study, and conducted a "face-to-face" interview. Patients answered the SNAC and, following a checklist evaluation instrument, the researcher prompted feedback from patients about the questionnaire instructions (eg, easy to follow?), responses (eg, easy to understand?), and questionnaire items (eg, were questions too technical, difficult to understand, offensive, too personal?). Patients were invited to contribute with open-ended unstructured feedback. The SNAC was also presented to 3 researchers with experience in patient recruitment. Patients, health professionals and researchers were asked to comment on the clarity and ambiguity of each item and question. The SNAC was pilot tested among further 9 patients. After the 51 items SNAC was reviewed for face and content validity, and pilot tested, the instrument was revised and the second draft of the SNAC including 50 items was formed.

\section{Psychometric Evaluation of the Newly Developed SNAC (50 Items)}

The psychometric properties of the 50-item SNAC were assessed using a multicentre cohort of people diagnosed with cirrhosis in Queensland, Australia. Patients were identified from appointment lists by a specialist nurse or hepatologist. Consecutive adult patients attending Hepatology/Gastroenterology clinics or admitted to the Royal Brisbane and Women's, Prince Charles, Mater, Logan and Princess Alexandra Hospitals with a diagnosis by a health-care provider of cirrhosis were eligible to participate. Patients were excluded if their treating clinician considered them to have a cognitive or physical impairment that could interfere with participation (eg, current encephalopathy, dementia) or if they were unable to communicate in English and an interpreter was not available to assist with the interview. A study nurse and a hepatologist assessed patients' eligibility, and the study nurse obtained written consent for participation in the study. The primary data included patient interviews conducted "face-to-face" at recruitment between June 2017 and December 2018. Some participants $(n=47)$ had part of their data collected using self-administered questionnaires when time to complete the face-to-face questionnaire was insufficient (eg, patient had to return to work, patient scheduled for imaging or a procedure).

Sociodemographic variables collected included individual-based measures (eg, age, sex, education level) and 
area-based measures for classification of rurality of residence $^{23}$ and the Index of Relative Socioeconomic Advantage and Disadvantage (IRSAD). ${ }^{24}$ The SNAC (50item version), two health-related quality of life tools (the generic Short Form 36 (SF-36) ${ }^{25}$ and disease-specific Chronic Liver Disease Questionnaire (CLDQ) ${ }^{19}$ ) and the Distress Thermometer (DT) ${ }^{26}$ were delivered verbally by an interviewer. Interviewers received standardized training, and interviews were monitored by the study coordinator (CB) for consistency across study sites. The SF- $36^{25}$ comprises 36 questions categorised into the following domains: general health, physical functioning, social functioning, pain, role limitations due to physical problems (rolephysical), emotional wellbeing, role limitations due to emotional problems (role-emotional) and vitality. Raw domain scores were converted into a $0-100$ scale, with a higher score indicating a higher health status; the overall score for each domain was calculated. The $\mathrm{CLDQ}^{19}$ measures 29 items on a 1-7 scale; the overall CLDQ score was calculated with a higher score indicating a higher health-related quality of life. The DT measures distress on a $0-10$ scale $\left(\right.$ zero $=$ no distress; $10=$ extreme distress) ${ }^{26}$

\section{Statistical Analysis}

The psychometric analyses of the SNAC were undertaken using SPSS statistical software (version 22; IBM Corporation, Armonk, NY). Two-tailed significance tests were conducted using a significance level of $p<0.05$. The SNAC response categories to the initial "yes" or "no" response to the opening question and the subsequent question with 4 possible answers were re-scored to ensure a linear response format using a 5-point response scale ( 0 indicates no issue with that item, no need for help; 1 indicates an issue with that item and "no" help required; 2 indicates an issue with that item and "A little" help required; 3 indicates an issue with that item and "Some" help required; 4 indicates an issue with that item and "A lot" of help required). Missing values for individual items were imputed using the participant's mean value for the relevant section of the questionnaire, provided that data was available for more than one half of the items in that section. Sample characteristics and prevalence of supportive needs, including flooring and ceiling effects, were summarized using descriptive statistics. In this study, we considered that ceiling and floor effects were present when over $15 \%$ of the participants selected the highest or lowest category, respectively. ${ }^{27}$
Exploratory factor analysis was used to assess the construct validity of the SNAC. The appropriateness of the sample size for conducting exploratory factor analysis was tested using the Bartlett test of sphericity and the Kaiser-Meyer-Olkin measure of sampling adequacy. Factors were identified using the Kaiser-Guttmann's criterion (Eigenvalues of 1.0 or greater) ${ }^{28}$ using principal components analysis, scree plots were used to determine at which point the decrease in Eigenvalues became negligible. Factor loadings equal to or greater than 0.5 were used as an indicator of factors to be retained; however, this information was considered alongside advice sought from a 6-person expert panel (4 hepatologists [EEP, PJC, RS, TR], 1 liver nurse [LH], and 1 pharmacist $[\mathrm{KH}]$ ). This panel was able to choose to retain potential instrument items that fell below the statistical ( 0.5 factor loading) threshold if they reached consensus that the item in question had important utility for informing the care of patients in clinical practice.

Reliability of the SNAC was confirmed by assessing test-retest reliability and internal consistency. Test-retest reliability was measured by re-administering the SNAC later on the same day to a group of 42 participants. A short time frame between the initial administration and re-administration of the tool was chosen because of the progressive nature of the disease, particularly decompensated cirrhosis. Typically, patients had their first interview as they arrived at the clinic and the second interview a few hours later, after their clinical appointment and/or tests. Individual items of the two sets of data were rescored using a 5-point scale (0-4, or missing) and compared using the Cohen's weighted kappa coefficient $(\kappa){ }^{29}$ According to convention, ${ }^{29}$ kappa values of $0-0.2$ indicate poor agreement, 0.21-0.4 fair, 0.41-0.6 moderate, $0.61-0.8$ substantial, and $0.81-1.0$ almost perfect agreement between the responses for individual items, and to satisfy the criteria for adequate external reliability in the SNAC. Internal consistency of the items in each subscale was assessed using Cronbach's alpha reliability coefficients, during item analysis.

Because there are unequal numbers of items in each subscale, the mean score was calculated for each subscale. Total SNAC score is the summation of the means of the four subscales. Convergent validity of the total SNAC score was tested against the SF- $36,{ }^{25}$ the CLDQ,${ }^{19}$ and the $\mathrm{DT}^{26}$ using the Spearman rank-order correlations (Spearman's rank correlation coefficients (Spearman's rho) are reported). We hypothesized that the total SNAC 
scores would correlate at least moderately $(>0.40)$ with these instruments. Discriminant validity of the total SNAC scores was tested using the Mann-Whitney test to compare selected participant subgroups.

\section{Ethical Approval}

Approval was obtained from the Human Research Ethics Committees of the QIMR Berghofer Medical Research Institute (P2207) and Metro South Health (HREC/16/ QPAH/628).

\section{Results}

\section{Pre-Testing of the First Draft of the SNAC (5I Items)}

Based on feedback from (i) a multi-disciplinary expert team of health professionals; (ii) the assessment of the face validity and acceptability of the 51-item instrument among 12 patients; and (iii) the pilot test among further 9 patients, the 51-item instrument was revised. The introductory question from two sections (about "day-to-day activities" and "information about liver disease") and nine items were changed to use more appropriate language (eg, from "Have decreased mobility" to "Have decreased ability to move around") and one item was deleted as it was very similar to another item in the questionnaire. The revised instrument with 50 items formed the second draft of SNAC.

\section{Participant Characteristics}

A total of 1065 patients with cirrhosis were identified during the recruitment period with 746 invited to participate in the study (581 interviewed, 165 declined; 78\% response). Patients who were not invited included 130 who failed to attend clinic, 112 who attended when a research officer was not available ("missed"), and 77 who were ineligible (30 of whom required an interpreter). Sixty-seven out of 581 patients had an interpreter or the carer assisted with the interview. During the initial recruitment stage, some interviewers misinterpreted the instructions for items 44-50 leading to some missing data (eg, opening questions were answered but subsequent questions about additional help were missing). After missing values for individual items were imputed, 465 complete interviews were included in the analysis, with a 9.3:1 ratio of participant-to-item. The characteristics of the final sample are shown in Table 1.
Table I Patient Demographic Information

\begin{tabular}{|c|c|c|}
\hline & & $N=465(\%)$ \\
\hline Age group & $\begin{array}{l}18-39 \text { years } \\
40-49 \text { years } \\
50-59 \text { years } \\
60-69 \text { years } \\
70+\text { years }\end{array}$ & $\begin{array}{l}20(4.3 \%) \\
66(14.2 \%) \\
145(31.2 \%) \\
150(32.3 \%) \\
84(18.1 \%)\end{array}$ \\
\hline Sex & $\begin{array}{l}\text { Female } \\
\text { Male }\end{array}$ & $\begin{array}{l}\mid 34 \text { (28.8\%) } \\
33 \mid \text { (7|.2\%) }\end{array}$ \\
\hline Marital status & $\begin{array}{l}\text { Married/De Facto } \\
\text { No partner (single, } \\
\text { separated/divorced, } \\
\text { widowed) } \\
\text { Not stated/unknown }\end{array}$ & $\begin{array}{l}222(47.7 \%) \\
240(51.6 \%) \\
3(0.6 \%)\end{array}$ \\
\hline Indigenous status & $\begin{array}{l}\text { Aboriginal and/or } \\
\text { Torres Strait Islander } \\
\text { Non-Indigenous }\end{array}$ & $\begin{array}{l}20(4.3 \%) \\
445(95.7 \%)\end{array}$ \\
\hline First language & $\begin{array}{l}\text { English } \\
\text { Not English } \\
\text { Not stated }\end{array}$ & $\begin{array}{l}397(85.4 \%) \\
67(14.4 \%) \\
I(0.2 \%)\end{array}$ \\
\hline Education & $\begin{array}{l}\text { Junior High School } \\
\text { or less } \\
\text { Senior High School } \\
\text { Trade/Diploma } \\
\text { University/College } \\
\text { Degree } \\
\text { Not stated }\end{array}$ & $\begin{array}{l}198(42.6 \%) \\
94(20.2 \%) \\
99(21.3 \%) \\
71(15.3 \%) \\
3(0.6 \%)\end{array}$ \\
\hline Employment status & $\begin{array}{l}\text { Employed } \\
\text { Not currently } \\
\text { employed }\end{array}$ & $\begin{array}{l}104(22.4 \%) \\
36 \mid(77.6 \%)\end{array}$ \\
\hline Lives alone & $\begin{array}{l}\text { No } \\
\text { Yes }\end{array}$ & $\begin{array}{l}337(72.5 \%) \\
128(27.5 \%)\end{array}$ \\
\hline Country of birth & $\begin{array}{l}\text { Australia } \\
\text { Asia } \\
\text { Other countries }\end{array}$ & $\begin{array}{l}331(71.3 \%) \\
61(13.2 \%) \\
69(15.0 \%)\end{array}$ \\
\hline $\begin{array}{l}\text { Index of Relative } \\
\text { Socioeconomic Advantage } \\
\text { and Disadvantage (IRSAD) }\end{array}$ & $\begin{array}{l}\text { Q1 most affluent } \\
\text { Q2 } \\
\text { Q3 } \\
\text { Q4 } \\
\text { Q5 Most } \\
\text { disadvantaged } \\
\text { Missing }\end{array}$ & $\begin{array}{l}97(20.9 \%) \\
140(30.1 \%) \\
69(14.8 \%) \\
79(17.0 \%) \\
77(16.6 \%) \\
3(0.6 \%)\end{array}$ \\
\hline Rurality of residence & $\begin{array}{l}\text { Major city } \\
\text { Outside major city } \\
\text { area }\end{array}$ & $\begin{array}{l}398(86.1 \%) \\
64(13.9 \%)\end{array}$ \\
\hline Recruiting hospital & $\begin{array}{l}\text { Princess Alexandra } \\
\text { Hospital }^{\mathrm{a}}\end{array}$ & $25 \mathrm{I}(54.0 \%)$ \\
\hline
\end{tabular}

(Continued) 
Table I (Continued).

\begin{tabular}{|l|l|l|}
\hline & & $\mathbf{N}=465(\%)$ \\
\hline & $\begin{array}{l}\text { Royal Brisbane \& } \\
\text { Women's Hospital }\end{array}$ & $83(17.8 \%)$ \\
& $\begin{array}{l}\text { The Prince Charles } \\
\text { Hospital }\end{array}$ & $52(11.2 \%)$ \\
& Logan Hospital & $42(9.0 \%)$ \\
& Mater Hospital & $37(8.0 \%)$ \\
\hline Patient admission status & Inpatient & $75(16.1 \%)$ \\
& Outpatient & $390(83.9 \%)$ \\
\hline
\end{tabular}

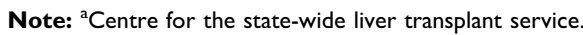

\section{Item Distribution}

Individual item raw means in the 50-item SNAC ranged from 0.06 to 1.83 (Table 2). All items were assessed for ceiling and floor effects. Items 3, 5, 7, 8, 24, and 41 showed a significant flooring effect ("no issue with that item" and "no need for help" responses endorsed by $>85 \%$ of participants). Items $3,5,7,24$, and 41 were deleted from subsequent analyses. Item 8 (language barrier) was included in the factor analysis because it was considered to be important for certain patient groups. No items had ceiling effects. Thus, 45 items (including item 8) were assessed using factor analysis.

\section{Factor Analysis}

The Kaiser-Meyer-Olkin statistic was 0.934, and Bartlett's test was significant (chi-square $=9386.7, \mathrm{p}<0.001$ ). Exploratory factor analysis was conducted based on the principle component with varimax rotation. The result of this analysis identified nine factors defined by the KaiserGuttman criterion (Eigenvalues $>1$ ). The scree plot showed a flattening after three-to-five factors (Figure 2); therefore models containing 3-, 4-, and 5-factors were considered.

The 3-factor model had adequate internal consistency (Cronbach's alpha $>0.70$ overall and for all subscales) and it accounted for $41.8 \%$ of the total variance. While the 5 -factor model had adequate overall internal consistency (Cronbach's alpha $>0.70$ ), and accounted for $47.9 \%$ of the total variance, the internal consistency of two subscales was $\leq 0.54$. A 4-factor model was identified to be most clinically significant and with adequate internal consistency. Results of factor analysis with 4-factor solution and varimax rotation are presented in Table 3. Findings indicated unique, strong factor loadings, and a strong foundation for subscale definition. Overall, 34 items achieved a factor loading of $>0.50$. At this point, the 6-person expert panel was consulted. There was a consensus (6-out-of-6) that five additional items $(8,9,12$, 19 , and 21) ought to be retained on the basis of their clinical significance. For items $9,12,19$, and 21 , more than $15 \%$ of the participants reported "Some"/“A lot" of need. While the prevalence of participants reporting "Some"/“A lot" of need for item 8 was low, it was retained because it may be important for certain patient sub-groups. Six items $(6,23,25,40,42$, and 43) failed to achieve a $>0.50$ factor loading, $<15 \%$ of the participants required "Some"/“A lot" of need, were considered not clinically significant by the 6-person expert panel, and were therefore excluded from the tool. The final 4 factors (subscales) including 39 items accounted for $49.2 \%$ of the total variance. Factor 1 (labelled "Psychosocial issues") relates to emotions, thoughts and relationships with others. Factor 2 ("Practical and physical needs") assesses symptoms and practical issues related to daily activities. Factor 3 ("Information needs") relates to access to support services and information requirements. Factor 4 ("Lifestyle changes") assesses a patient's needs with regards to lifestyle changes such as diet and physical activity.

\section{Scale Reliability}

Overall, the rate of missing data of the 50-item version of the SNAC was $4.3 \%$. For 39 of the 50 items the rate of missing data was $<1 \%$. Missing-ness was driven by the interviewer error for items 44 to 50 (with which we had initial data collection problems); the rate of missing data for these items was over $10 \%$. The rate of missing data for items $44-50$ decreased (ranging from $2.4 \%$ to $4.8 \%$ ), with retraining of interviewers and collection of test-retest data. Analysis of test-retest reliability showed adequate external reliability in the SNAC. The kappa coefficient for 42 items (84\%) exceeded 0.60 indicating substantial agreement (for 18 out of these 42 items $k>0.80)$, for 7 items $(14 \%)$ the kappa coefficient was between 0.41 and 0.60 , and for 1 item ( $2 \%$; "Stop or limit substance use") it was 0.27 (fair agreement). The latter was likely due to a high penalty within the calculation of the kappa coefficient due to high expected agreement as most participants did not report a need for this item. ${ }^{30}$ Cronbach's alpha values for the four subscales ranging from 0.64 to 0.92 indicated satisfactory internal consistency (Table 3 ).

\section{Convergent Validity}

We hypothesized that higher supportive needs are negatively correlated with health-related quality of life and positively correlated with distress. The total SNAC score 
Table 2 Item Mean and Percentage of Sample Stratified by Level of Unmet Need

\begin{tabular}{|c|c|c|c|c|c|c|c|c|}
\hline $\begin{array}{l}\text { Item } \\
\text { No. }\end{array}$ & Item & Mean & SD & $\begin{array}{l}\text { No Issue } \\
\text { No Need }\end{array}$ & $\begin{array}{l}\text { Issue No } \\
\text { Need }\end{array}$ & A Little & Some & A Lot \\
\hline I & $\begin{array}{l}\text { Have extra costs involved in managing your liver } \\
\text { condition }\end{array}$ & 0.89 & 1.35 & 297 (63.9\%) & $42(9.0 \%)$ & $40(8.6 \%)$ & $52(11.2 \%)$ & $34(7.3 \%)$ \\
\hline 2 & $\begin{array}{l}\text { Have any issues with transport getting to and from } \\
\text { medical appointments for your liver condition }\end{array}$ & 0.75 & 1.40 & $350(75.3 \%)$ & $12(2.6 \%)$ & $20(4.3 \%)$ & $36(7.7 \%)$ & $47(10.1 \%)$ \\
\hline 3 & Have difficulty looking after yourself (eg, showering) & 0.43 & 1.10 & $396(85.2 \%)$ & $9(1.9 \%)$ & $19(4.1 \%)$ & $13(2.8 \%)$ & $28(6.0 \%)$ \\
\hline 4 & $\begin{array}{l}\text { Have difficulty with daily tasks around the house (eg, } \\
\text { washing, cooking, raking the yard, sweeping the floor) }\end{array}$ & 1.10 & 1.56 & $289(62.2 \%)$ & $28(6.0 \%)$ & $30(6.5 \%)$ & $48(10.3 \%)$ & $70(15.1 \%)$ \\
\hline 5 & Have to stop or have problems with driving & 0.27 & 0.90 & $417(89.7 \%)$ & $14(3.0 \%)$ & $8(1.7 \%)$ & $7(1.5 \%)$ & $19(4.1 \%)$ \\
\hline 6 & $\begin{array}{l}\text { Have trouble attending multiple clinic visits or hospital } \\
\text { admissions }\end{array}$ & 0.49 & 1.16 & $382(82.2 \%)$ & $16(3.4 \%)$ & $16(3.4 \%)$ & $23(4.9 \%)$ & $28(6.0 \%)$ \\
\hline 7 & $\begin{array}{l}\text { Have trouble making a medical appointment due to } \\
\text { language barriers }\end{array}$ & 0.06 & 0.45 & $456(98.1 \%)$ & $2(0.4 \%)$ & I (0.2\%) & I (0.2\%) & $5(1.1 \%)$ \\
\hline 8 & Have trouble filling in forms due to language barriers & 0.09 & 0.56 & $45 \mathrm{I}(97.0 \%)$ & $2(0.4 \%)$ & $2(0.4 \%)$ & $3(0.6 \%)$ & $7(1.5 \%)$ \\
\hline 9 & $\begin{array}{l}\text { Did your job performance decrease because of your } \\
\text { health }\end{array}$ & 0.84 & 1.44 & $323(69.5 \%)$ & $36(7.7 \%)$ & $17(3.7 \%)$ & $34(7.3 \%)$ & $55(11.8 \%)$ \\
\hline 10 & Feel unwell & 1.39 & 1.53 & $212(45.6 \%)$ & $7 \mid(15.3 \%)$ & $37(8.0 \%)$ & $78(16.8 \%)$ & $67(14.4 \%)$ \\
\hline 11 & Have lack of energy, tiredness & 1.83 & 1.50 & $119(25.6 \%)$ & $116(24.9 \%)$ & $56(12.0 \%)$ & $75(16.1 \%)$ & $99(21.3 \%)$ \\
\hline 12 & Sleep poorly & 1.65 & 1.59 & $174(37.4 \%)$ & $82(17.6 \%)$ & $38(8.2 \%)$ & $77(16.6 \%)$ & $94(20.2 \%)$ \\
\hline 13 & Have confusion, disorientation, personality changes & 0.88 & 1.35 & $306(65.8 \%)$ & $27(5.8 \%)$ & $48(10.3 \%)$ & $51(11.0 \%)$ & $33(7.1 \%)$ \\
\hline 14 & Have decreased ability to get around & 0.95 & 1.42 & $295(63.4 \%)$ & $37(8.0 \%)$ & $39(8.4 \%)$ & $49(10.5 \%)$ & $45(9.7 \%)$ \\
\hline 15 & Have swelling of the ankles and legs & 1.06 & 1.42 & $268(57.6 \%)$ & $50(10.8 \%)$ & $42(9.0 \%)$ & $63(13.5 \%)$ & $42(9.0 \%)$ \\
\hline 16 & Have itchy skin & 1.15 & 1.43 & $243(52.3 \%)$ & $61(13.1 \%)$ & $61(13.1 \%)$ & $49(10.5 \%)$ & $51(11.0 \%)$ \\
\hline 17 & Have loss of appetite, nausea or vomiting & 1.07 & 1.44 & $264(56.8 \%)$ & $53(11.4 \%)$ & $53(11.4 \%)$ & $41(8.8 \%)$ & $54(11.6 \%)$ \\
\hline 18 & Have ascites (fluid build up in the abdomen/belly) & 1.01 & 1.47 & $290(62.4 \%)$ & $39(8.4 \%)$ & $34(7.3 \%)$ & $47(10.1 \%)$ & $55(11.8 \%)$ \\
\hline 19 & Have easy bruising, bleeding, thinning of the skin & 1.10 & 1.31 & $208(44.7 \%)$ & $128(27.5 \%)$ & $42(9.0 \%)$ & $47(10.1 \%)$ & $40(8.6 \%)$ \\
\hline 20 & $\begin{array}{l}\text { Have side effects of treatment (eg, frequent or loose } \\
\text { bowel motions, bloating and abdominal discomfort) }\end{array}$ & 0.80 & 1.34 & $319(68.6 \%)$ & $35(7.5 \%)$ & $26(5.6 \%)$ & $53(11.4 \%)$ & $32(6.9 \%)$ \\
\hline 21 & $\begin{array}{l}\text { Make lifestyle changes to increase exercise or lose } \\
\text { weight }\end{array}$ & 0.88 & 1.34 & $288(61.9 \%)$ & $65(14.0 \%)$ & $32(6.9 \%)$ & $4 \mathrm{I}(8.8 \%)$ & 39 (8.4\%) \\
\hline 22 & $\begin{array}{l}\text { Make diet changes (eg, low salt diet or decrease } \\
\text { portion size) }\end{array}$ & 1.13 & 1.38 & $223(48.0 \%)$ & $102(21.9 \%)$ & $41(8.8 \%)$ & $53(11.4 \%)$ & 46 (9.9\%) \\
\hline 23 & Stop or limit alcohol use & 0.73 & 1.22 & $291(62.6 \%)$ & 101 (2I.7\%) & 17 (3.7\%) & $18(3.9 \%)$ & $38(8.2 \%)$ \\
\hline 24 & $\begin{array}{l}\text { Stop or limit substance use (eg, injecting drugs, } \\
\text { marijuana) }\end{array}$ & 0.11 & 0.51 & $438(94.2 \%)$ & $13(2.8 \%)$ & $7(1.5 \%)$ & $4(0.9 \%)$ & $3(0.6 \%)$ \\
\hline 25 & $\begin{array}{l}\text { Feel unsure about the safety of over the counter, } \\
\text { complementary or alternative medicines }\end{array}$ & 0.47 & 1.02 & $361(77.6 \%)$ & 45 (9.7\%) & $22(4.7 \%)$ & $20(4.3 \%)$ & $17(3.7 \%)$ \\
\hline 26 & $\begin{array}{l}\text { Have fear of the unknown or uncertainty about the } \\
\text { future }\end{array}$ & 1.14 & 1.46 & $252(54.2 \%)$ & $57(12.3 \%)$ & $47(10.1 \%)$ & $56(12.0 \%)$ & $53(11.4 \%)$ \\
\hline 27 & Have any feelings about death and dying & 0.83 & 1.29 & $298(64.1 \%)$ & $56(12.0 \%)$ & 37 (8.0\%) & $42(9.0 \%)$ & $32(6.9 \%)$ \\
\hline 28 & Feel down or depressed & 1.20 & 1.43 & $231(49.7 \%)$ & $68(14.6 \%)$ & $54(11.6 \%)$ & $66(14.2 \%)$ & $46(9.9 \%)$ \\
\hline 29 & Feel lonely & 0.77 & 1.26 & $305(65.6 \%)$ & $58(12.5 \%)$ & $35(7.5 \%)$ & $36(7.7 \%)$ & $31(6.7 \%)$ \\
\hline 30 & Feel confused about managing your liver condition & 0.59 & 1.21 & $363(78.1 \%)$ & $16(3.4 \%)$ & $28(6.0 \%)$ & $31(6.7 \%)$ & $27(5.8 \%)$ \\
\hline 31 & Feel frustrated & 1.11 & 1.43 & $251(54.0 \%)$ & $68(14.6 \%)$ & $40(8.6 \%)$ & $57(\mid 2.3 \%)$ & $49(10.5 \%)$ \\
\hline 32 & Have anxiety and/or stress & 1.28 & 1.49 & $229(49.2 \%)$ & $61(13.1 \%)$ & $49(10.5 \%)$ & $68(14.6 \%)$ & $58(12.5 \%)$ \\
\hline 33 & Have aggression, irritability, anger & 0.70 & 1.20 & $321(69.0 \%)$ & $44(9.5 \%)$ & $37(8.0 \%)$ & 44 (9.5\%) & $19(4.1 \%)$ \\
\hline 34 & Have lack of interest, no "get up and go" & 1.19 & 1.40 & $223(48.0 \%)$ & $82(17.6 \%)$ & $50(10.8 \%)$ & $67(14.4 \%)$ & $43(9.2 \%)$ \\
\hline 35 & Feel ashamed or embarrassed because of social stigma & 0.49 & 1.06 & $364(78.3 \%)$ & $32(6.9 \%)$ & $28(6.0 \%)$ & $24(5.2 \%)$ & $17(3.7 \%)$ \\
\hline 36 & Have fears about losing your independence & 0.80 & 1.30 & $306(65.8 \%)$ & $55(11.8 \%)$ & $33(7.1 \%)$ & $34(7.3 \%)$ & $37(8.0 \%)$ \\
\hline 37 & Fear being a burden to those close to you & 0.94 & 1.39 & $285(61.3 \%)$ & $53(11.4 \%)$ & $43(9.2 \%)$ & $37(8.0 \%)$ & $47(10.1 \%)$ \\
\hline 38 & Worry about the worries of those close to you & 1.22 & 1.43 & $214(46.0 \%)$ & $97(20.9 \%)$ & $45(9.7 \%)$ & $54(11.6 \%)$ & $55(11.8 \%)$ \\
\hline 39 & $\begin{array}{l}\text { Worry about your illness getting worse (eg, developing } \\
\text { liver cancer) }\end{array}$ & 1.32 & 1.47 & $206(44.3 \%)$ & $90(19.4 \%)$ & $44(9.5 \%)$ & $66(14.2 \%)$ & $59(12.7 \%)$ \\
\hline
\end{tabular}

(Continued) 
Table 2 (Continued).

\begin{tabular}{|c|c|c|c|c|c|c|c|c|}
\hline $\begin{array}{l}\text { Item } \\
\text { No. }\end{array}$ & Item & Mean & SD & $\begin{array}{l}\text { No Issue } \\
\text { No Need }\end{array}$ & $\begin{array}{l}\text { Issue No } \\
\text { Need }\end{array}$ & A Little & Some & A Lot \\
\hline 40 & Have changes in sexual life & 0.52 & 1.14 & $361(77.6 \%)$ & $41(8.8 \%)$ & $16(3.4 \%)$ & $18(3.9 \%)$ & $29(6.2 \%)$ \\
\hline 41 & Worry about infecting family or others & 0.28 & 0.89 & $412(88.6 \%)$ & $16(3.4 \%)$ & $10(2.2 \%)$ & $12(2.6 \%)$ & $15(3.2 \%)$ \\
\hline 42 & Have concerns around liver transplant & 0.51 & 1.14 & $372(80.0 \%)$ & $26(5.6 \%)$ & $17(3.7 \%)$ & $24(5.2 \%)$ & $26(5.6 \%)$ \\
\hline 43 & $\begin{array}{l}\text { Felt unsure because different information was provided } \\
\text { by different doctors or specialists }\end{array}$ & 0.69 & 1.28 & $339(72.9 \%)$ & $30(6.5 \%)$ & $27(5.8 \%)$ & $37(8.0 \%)$ & $32(6.9 \%)$ \\
\hline 44 & $\begin{array}{l}\text { Obtain information to use at home about how to } \\
\text { manage your illness and complications }\end{array}$ & 1.18 & 1.18 & $156(33.5 \%)$ & $178(38.3 \%)$ & $46(9.9 \%)$ & $60(12.9 \%)$ & $25(5.4 \%)$ \\
\hline 45 & Have tests/procedures explained & 0.78 & 1.25 & $301(64.7 \%)$ & $61(13.1 \%)$ & $33(7.1 \%)$ & $44(9.5 \%)$ & $26(5.6 \%)$ \\
\hline 46 & $\begin{array}{l}\text { Have the benefits and side-effects of treatments } \\
\text { explained }\end{array}$ & 0.89 & 1.22 & $259(55.7 \%)$ & $89(19.1 \%)$ & $46(9.9 \%)$ & $50(10.8 \%)$ & $21(4.5 \%)$ \\
\hline 47 & $\begin{array}{l}\text { Access professional help/counselling (eg, from social } \\
\text { worker, psychologist, nurse specialist) }\end{array}$ & 1.03 & 1.10 & $177(38.1 \%)$ & $186(40.0 \%)$ & $27(5.8 \%)$ & $63(13.5 \%)$ & $12(2.6 \%)$ \\
\hline 48 & Know who to call and when to call for medical help & 0.45 & 1.04 & $377(81.1 \%)$ & $24(5.2 \%)$ & $21(4.5 \%)$ & $29(6.2 \%)$ & $14(3.0 \%)$ \\
\hline 49 & $\begin{array}{l}\text { Were you informed about things you can do to help } \\
\text { yourself to get well }\end{array}$ & 0.95 & 1.36 & $276(59.4 \%)$ & $65(14.0 \%)$ & $34(7.3 \%)$ & $52(11.2 \%)$ & $38(8.2 \%)$ \\
\hline 50 & Were you informed about support groups in your area & 1.11 & 1.14 & $163(35.1 \%)$ & 182 (39.1\%) & 42 (9.0\%) & 60 (12.9\%) & $18(3.9 \%)$ \\
\hline
\end{tabular}

correlated strongly with the $\mathrm{CLDQ}^{19}$ (Spearman rho= $-0.68 ; \mathrm{p}<0.001)$ and moderately with $\mathrm{DT}^{26}$ scores (Spearman rho $=0.53 ; \mathrm{p}<0.001)$ and seven subscales of the SF-36, ${ }^{25}$ namely: vitality, mental health, social functioning, bodily pain, general health, role-emotional, and role-physical (Spearman rho ranged from -0.48 to -0.57 ; $\mathrm{p}<0.001$ ) (Supplementary Figure 1). The total SNAC score correlated fairly with the SF-36 physical functioning subscale (Spearman rho $-0.38 ; \mathrm{p}<0.001$ ).

\section{Discriminant Validity}

We hypothesized that older patients and patients with cirrhosis complications have higher total SNAC scores

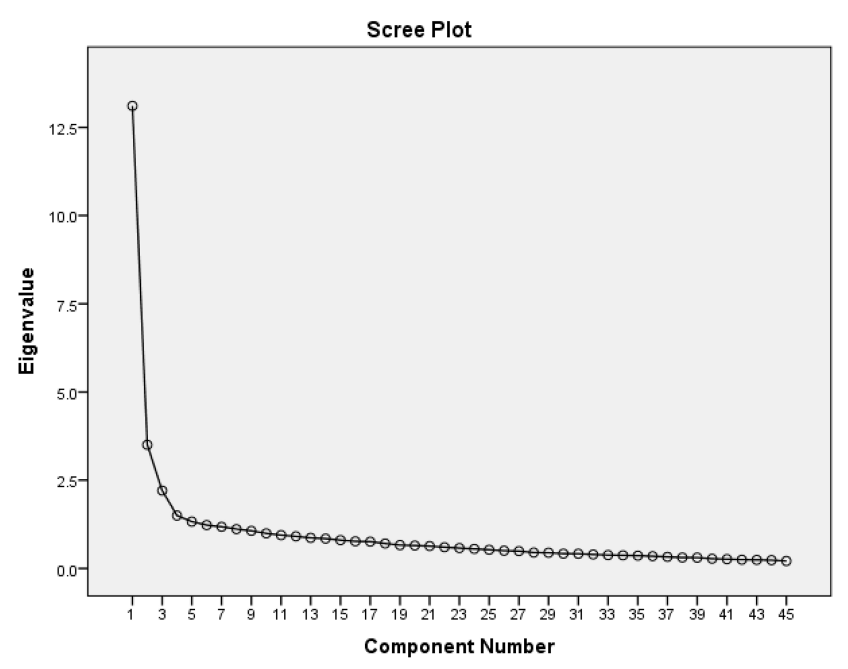

Figure 2 The scree plot of eigenvalues showing the number of factors. than younger patients and patients without cirrhosis complications. The SNAC discriminated between the supportive needs of certain key participant subgroups. Females $(\mathrm{p}=0.013)$, patients younger than 50 years $(\mathrm{p}<0.001)$, and those who were recruited as inpatients with cirrhosis complications vs ambulatory patients recruited via clinics $(p<0.001)$ had significantly higher average total SNAC scores than their respective counterparts. There was no statistically significant difference in average SNAC score by Indigenous Australians $(\mathrm{p}=0.079)$, lived alone vs not $(\mathrm{p}=0.060)$, hospital $(\mathrm{p}=0.220)$, patient education $(\mathrm{p}=0.320)$, marital status $(p=0.270)$, rurality of residence $(p=0.450)$, and socioeconomic advantage and disadvantage $(\mathrm{p}=0.890)$.

\section{Further Refinement of the Items}

The wording of item 8 was revised to incorporate item 7 ("Have trouble making a medical appointment or filling in forms due to language barriers"). Following issues with missing data for items 44-50, the layout of this section in the interview was changed. For items 44-50, the subsequent question ("How much additional help did/do you need?") was added under the opening question, so it is clear that both questions must be answered. We have also revised the instructions and additional instructions and examples were also added for this section. The layout remained unchanged for the other questions where the opening question was displayed side-by-side with the subsequent question. The 
Table 3 All Factor Categories and Loadings, and Internal Consistency of Each Subscale of the SNAC

\begin{tabular}{|c|c|c|c|c|c|}
\hline & Item & $\begin{array}{l}\text { Factor I } \\
14 \text { Items } \\
\text { Cronbach's } \\
\text { Alpha= } 0.92\end{array}$ & $\begin{array}{l}\text { Factor } 2 \\
16 \text { Items } \\
\text { Cronbach's } \\
\text { Alpha }=0.89\end{array}$ & $\begin{array}{l}\text { Factor } 3 \\
7 \text { Items } \\
\text { Cronbach's } \\
\text { Alpha }=\mathbf{0 . 8 7}\end{array}$ & $\begin{array}{l}\text { Factor } 4 \\
2 \text { Items } \\
\text { Cronbach's } \\
\text { Alpha }=0.64\end{array}$ \\
\hline 1 & Have extra costs involved in managing your liver condition & & 0.57 & & \\
\hline 2 & $\begin{array}{l}\text { Have any issues with transport getting to and from medical appointments for your } \\
\text { liver condition }\end{array}$ & & 0.50 & & \\
\hline 4 & $\begin{array}{l}\text { Have difficulty with daily tasks around the house (eg, washing, cooking, raking the yard, } \\
\text { sweeping the floor) }\end{array}$ & & 0.63 & & \\
\hline $6^{\mathrm{b}}$ & Have trouble attending multiple clinic visits or hospital admissions & - & - & - & - \\
\hline $8^{\mathrm{a}, \mathrm{c}}$ & Have trouble filling in forms due to language barriers & & 0.18 & & \\
\hline 9 & Did your job performance decrease because of your health & & 0.47 & & \\
\hline 10 & Feel unwell & & 0.65 & & \\
\hline 11 & Have lack of energy, tiredness & & 0.68 & & \\
\hline 12 & Sleep poorly & & 0.46 & & \\
\hline 13 & Have confusion, disorientation, personality changes & & 0.52 & & \\
\hline 14 & Have decreased ability to get around & & 0.68 & & \\
\hline 15 & Have swelling of the ankles and legs & & 0.56 & & \\
\hline 16 & Have itchy skin & & 0.51 & & \\
\hline 17 & Have loss of appetite, nausea or vomiting & & 0.60 & & \\
\hline 18 & Have ascites (fluid build up in the abdomen/belly) & & 0.60 & & \\
\hline 19 & Have easy bruising, bleeding, thinning of the skin & & 0.46 & & \\
\hline 20 & $\begin{array}{l}\text { Have side effects of treatment (eg, frequent or loose bowel motions, bloating and } \\
\text { abdominal discomfort) }\end{array}$ & & 0.61 & & \\
\hline 21 & Make lifestyle changes to increase exercise or lose weight & & & & 0.46 \\
\hline 22 & Make diet changes (eg, low salt diet or decrease portion size) & & & & 0.60 \\
\hline $23^{\mathrm{b}}$ & Stop or limit alcohol use & - & - & - & - \\
\hline $25^{\mathrm{b}}$ & $\begin{array}{l}\text { Feel unsure about the safety of over the counter, complementary or alternative } \\
\text { medicines }\end{array}$ & - & - & - & - \\
\hline 26 & Have fear of the unknown or uncertainty about the future & 0.77 & & & \\
\hline 27 & Have any feelings about death and dying & 0.65 & & & \\
\hline 28 & Feel down or depressed & 0.76 & & & \\
\hline 29 & Feel lonely & 0.66 & & & \\
\hline 30 & Feel confused about managing your liver condition & 0.55 & & & \\
\hline 31 & Feel frustrated & 0.68 & & & \\
\hline 32 & Have anxiety and/or stress & 0.71 & & & \\
\hline 33 & Have aggression, irritability, anger & 0.58 & & & \\
\hline 34 & Have lack of interest, no "get up and go" & 0.57 & & & \\
\hline 35 & Feel ashamed or embarrassed because of social stigma & 0.61 & & & \\
\hline 36 & Have fears about losing your independence & 0.58 & & & \\
\hline 37 & Fear being a burden to those close to you & 0.67 & & & \\
\hline 38 & Worry about the worries of those close to you & 0.65 & & & \\
\hline 39 & Worry about your illness getting worse (eg, developing liver cancer) & 0.59 & & & \\
\hline $40^{\mathrm{b}}$ & Have changes in sexual life & - & - & - & - \\
\hline $42^{b}$ & Have concerns around liver transplant & - & - & - & - \\
\hline $43^{b}$ & Felt unsure because different information was provided by different doctors or specialists & - & - & - & - \\
\hline 44 & Obtain information to use at home about how to manage your illness and complications & & & 0.76 & \\
\hline 45 & Have tests/procedures explained & & & 0.74 & \\
\hline 46 & Have the benefits and side-effects of treatments explained & & & 0.79 & \\
\hline 47 & Access professional help/counselling (eg, from social worker, psychologist, nurse specialist) & & & 0.69 & \\
\hline 48 & Know who to call and when to call for medical help & & & 0.57 & \\
\hline 49 & Were you informed about things you can do to help yourself to get well & & & 0.79 & \\
\hline 50 & Were you informed about support groups in your area & & & 0.71 & \\
\hline
\end{tabular}

Notes: altem 8 (language barriers) showed a significant flooring effect and was included in the factor analysis because it was considered to be important for certain patient groups; 'ltems 6, 23, 25, 40, 42, and 43 were not been retained in the SNAC; 'In the final SNAC item 8 was re-worded to "Have trouble making a medical appointment or filling in forms due to language barriers". 
final SNAC (39 items) and its instructions are provided as online Supplementary material.

\section{Prevalence of Supportive Needs Items}

Most participants (377 out of $465,81.1 \%$ ) reported that they needed "Some"/"A lot" of additional help with at least one item. The 10 most frequently reported unmet needs ("Some"/ "A lot" of additional help) included: "Lack of energy" (37.4\%), "Slept poorly" (36.8\%), "Feel unwell" (31.2\%), "Felt Anxious/Stressed" (27.1\%), "Worried about illness getting worse" (26.9\%), "Difficulty with daily tasks" (25.4\%), "Felt Depressed" (24.1\%), "Had Lack of interest" (23.7\%), "Fear of the unknown/Uncertainty about the future" (23.4\%), and "Worried about the worries of those close to you" (23.4\%). The "Practical and physical needs" and "Psychosocial issues" subscales had the largest number of items where participants reported that they needed "Some"/ "A lot" of additional help, $69.9 \%$ and $56.5 \%$ of items, respectively.

\section{Discussion}

Our findings provide initial evidence for the validity and reliability of the SNAC, a disease-specific 39-item instrument designed to measure type and amount of perceived supportive needs of people diagnosed with cirrhosis. The SNAC met the requirements of a needs assessment instrument and identified a range of needs important to patients with cirrhosis, grouped in four subscales: "Psychosocial issues", "Practical and physical needs", "Information needs", and "Lifestyle changes".

The SNAC items, generated based on a comprehensive review $^{13}$ and a cross-sectional study exploring patients' needs, ${ }^{12}$ were assessed for face and content validity, piloted using patients with cirrhosis, and the instrument was duly revised. Through exploratory factor analysis, the instrument was reduced from 50 to 39 items considered to be clinically relevant items by the expert multidisciplinary panel, and grouped into four subscales. The KaiserMeyer-Olkin statistic and the Bartlett test of sphericity confirmed sampling and data adequacy for conducting the exploratory factor analysis.

As there is no gold standard instrument for supportive needs in cirrhosis, we selected validated measures of healthrelated quality of life $\left(\mathrm{CLDQ}^{19}\right.$ and SF-36 $\left.6^{25}\right)$ and distress (distress thermometer) in order to assess convergent validity. ${ }^{26}$ Our results supported the hypotheses that higher supportive needs are negatively correlated with quality of life and positively correlated with distress, supporting convergent validity of the SNAC. Furthermore, our findings concur with prior studies. Janani et $\mathrm{al}^{31}$ reported that SF-36 and CLDQ scores were lower in cirrhosis patients with Child-Turcotte-Pugh class C, and CLDQ score was lower in younger patients ( $\leq 45$ years). Khairullah $\&$ Mahadeva $^{32}$ reported that CLDQ scores were significantly lower for patients with decompensated cirrhosis compared to compensated or no cirrhosis. In this study, there were differences in SNAC total scores according to disease stage and patient's age which supports known group validity.

Patients recruited from five large hospitals in Queensland, including the Princess Alexandra Hospital that is the referral centre for the state-wide liver transplant service, provided data for this study. Nevertheless, study findings may not be directly generalisable to all patients with cirrhosis in Australia or other English-speaking countries. While overall the psychometric properties of the SNAC were good, its explained variance $(49.2 \%)$ is lower than that reported for many other comparable tools. Compared to other supportive care measures reporting a reduced total variance, the SNAC had a relatively small sample size relative to the number of items examined. For example, the supportive cancer care needs assessment tool for Indigenous people with cancer (SCNAT-IP) ${ }^{17}$ explained $51 \%$ of the variance, the systemic lupus erythematosus needs questionnaire (SLENQ) ${ }^{33}$ explained $53 \%$, and the Cancer Survivors' Unmet Needs measure $(\mathrm{CaSUN})^{18}$ explained 54\%. The validation of the SCNAT-IP was undertaken in a study of 248 participants (39 items were examined, 6.4 participants per item), ${ }^{17}$ while the SLENQ included 386 participants (97 items, 4.0 participants per item), ${ }^{33}$ and the CaSUN included 353 participants (46 items, 7.7 participants per item).$^{18}$ It has been suggested that, as a benchmark, 5 participants per item are needed for the development of a new scale. ${ }^{34}$ In the current study, 9.6 participants per item were included. The small number of patients piloting the reviseddraft of SNAC is a limitation. The lower explained variance reported here is potentially due to differing needs of patients at different stages of their disease. Patients' symptoms and disease management issues in compensated cirrhosis are very different from those of patients who have a history of prior decompensation, or patients who are current inpatients with complications of cirrhosis (ie, decompensation) at the time of recruitment. In developing the SNAC, all of these three patient groups were included. However, the sample size was too small to allow subgroup analysis of current inpatients with cirrhosis complications. In future studies, patients should be differentiated by MELD or Child-Pugh score 
rather than by ambulatory or inpatient status, a cruder measure of disease severity.

Chronic liver disease disproportionately affects ethnic minority groups in many developed countries. ${ }^{7,22,35-38}$ Similar to other studies in underserved and minority patient populations, we used data collection methods suited to these populations. ${ }^{17,39}$ Future research could compare selfadministered and interviewer-administered response patterns. While the overall rate of missing data was comparable to other supportive care tools, it is important to note that missing data was due to some interviewers misinterpreting the instructions for the seven "Information needs" items, for which we revised the instructions and after which the remaining cases had completed data for those items. The 39-item SNAC should be tested further in larger studies including patients from different ethnic backgrounds, disease aetiologies and varying levels of disease severity. Future qualitative research should explore which supportive needs are not adequately represented by the 39 items and how additional questions could capture these needs, and assess the face and content validity of the SNAC for particular ethnic minority groups (eg, Indigenous Australians).

To the best of our knowledge, this is the first study to comprehensively identify the specific unmet needs of patients with cirrhosis and identify those areas in which additional assistance is required. The highest ranked unmet needs were "Practical and physical needs" and "Psychosocial issues". Completion of this tool with patients may enhance their communication with the health-care team and raise awareness of the wider needs of patients and their caregivers. It is important to ensure that a spectrum of supportive care services is available for cirrhosis patients who need them. The tool will allow health professionals to identify the level of a patient's perceived need. For example, a patient who reported having issues with his/her diet in the past month, who discussed this with his/her primary care clinician, and subsequently reports "none" or "little" need for additional help with this issue, may not require referral to a dietician. On the contrary, a similar patient who has not seen a health professional about his/her diet and reports requiring "Some" or "A lot" of additional with this, may benefit from referral.

Despite certain recognised limitations, the results provide robust initial evidence supporting the properties of the SNAC. This study lays the foundation for further studies in this area. A supportive needs assessment tool for patients with cirrhosis is necessary to identify populationlevel needs for care and to provide a robust scientific basis to lobby for resources and policy response. For individual patients, health-care professionals should endeavour to provide supportive care that is tailored to individual needs and disease severity. As cirrhosis may be a progressive disease, a tool that reliably identifies the changing needs of patients according to disease severity would also be invaluable; longitudinal data is needed. Accurately assessing individual patient's supportive care needs has potential utility in clinical practice to promote patient-centred care and for facilitating timely referrals to diverse multidisciplinary support services. Utilization of the SNAC by care providers at each visit may be used to monitor resolution of unmet needs identified in previous visits and to identify persistent or emerging needs. Finally, the factor structure of the SNAC and its validity as a measure of unmet needs should be examined in different settings.

\section{Acknowledgments}

PC Valery was supported by a NHMRC Career Development Fellowship (\#1083090). SM McPhail was supported by a NHMRC fellowship (\#1090440). The funders had no role in study design, data collection, data analysis, interpretation, or writing of the manuscript. We thank the staff and patients of the participating hospitals for their assistance and cooperation in performing the current study. We thank Joo Hyun Kwon, Isanka Umayangani Ratnasekera, Francisca Powell, and Stefania Massignam for assistance with patient recruitment and interview.

\section{Author Contributions}

PCV and EEP contributed to the conception and design of the study. EEP, RS, PJC, TR, and RG assisted with identification of patients for the study, and CMB and RG recruited participants. PCV performed the data analysis. $\mathrm{GH}$ and SMM provided statistical advice. All authors contributed to data analysis, drafting and revising the article, gave final approval of the version to be published, and agree to be accountable for all aspects of the work.

\section{Disclosure}

The authors report no conflicts of interest in this work.

\section{References}

1. Fagan KJ, Zhao EY, Horsfall LU, et al. Burden of decompensated cirrhosis and ascites on hospital services in a tertiary care facility: time for change? Int Med J. 2014;44(9):865-872. doi:10.1111/imj.2014.44. issue-9 
2. Deloitte Access Economics. The Economic Cost and Health Burden of Liver Diseases in Australia. Sydney: Gastroenterological Society of Australia/Australian Liver Association; 2013.

3. ABS. Causes of Death, Australia, 2015. Canberra; 2016.

4. Schuppan D, Afdhal NH. Liver cirrhosis. Lancet. 2008;371 (9615):838-851. doi:10.1016/S0140-6736(08)60383-9

5. Grattagliano I, Ubaldi E, Bonfrate L, Portincasa P. Management of liver cirrhosis between primary care and specialists. World J Gastroenterol. 2011;17(18):2273-2282. doi:10.3748/wjg.v17.i18.2273

6. Wang FS, Fan JG, Zhang Z, Gao B, Wang HY. The global burden of liver disease: the major impact of China. Hepatology. 2014;60 (6):2099-2108. doi:10.1002/hep.27406

7. Scaglione S, Kliethermes S, Cao G, et al. The epidemiology of cirrhosis in the United States: a population-based study. J Clin Gastroenterol. 2015;49(8):690-696. doi:10.1097/MCG.00000000000 00208

8. Mokdad AA, Lopez AD, Shahraz S, et al. Liver cirrhosis mortality in 187 countries between 1980 and 2010: a systematic analysis. BMC Med. 2014;12:145. doi:10.1186/s12916-014-0145-y

9. Fleming KM, Aithal GP, Card TR, West J. All-cause mortality in people with cirrhosis compared with the general population: a population-based cohort study. Liver Int. 2012;32(1):79-84. doi:10.1111/liv.2011.32.issue-1

10. EASL. EASL clinical practice guidelines on the management of ascites, spontaneous bacterial peritonitis, and hepatorenal syndrome in cirrhosis. $J$ Hepatol. 2010;53(3):397-417. doi:10.1016/j. jhep.2010.05.004

11. Low JTS, Rohde G, Pittordou K, et al. Supportive and palliative care in people with cirrhosis: International systematic review of the perspective of patients, family members and health professionals. J Hepatol. 2018;69(6):1260-1273. doi:10.1016/j.jhep.2018.08.028

12. Valery PC, Clark PJ, McPhail SM, et al. Exploratory study into the unmet supportive needs of people diagnosed with cirrhosis in Queensland, Australia. Intern Med J. 2017;47(4):429-435. doi:10.1111/imj.2017.47.issue-4

13. Valery PC, Powell E, Moses N, et al. Systematic review: unmet supportive care needs in people diagnosed with chronic liver disease. BMJ Open. 2015;5(4):e007451-e. doi:10.1136/bmjopen2014-007451

14. Cramp F, Bennett MI. Development of a generic working definition of 'supportive care'. BMJ Support Palliat Care. 2013;3(1):53-60. doi:10.1136/bmjspcare-2012-000222

15. Ponzio M, Tacchino A, Zaratin P, Vaccaro C, Battaglia MA. Unmet care needs of people with a neurological chronic disease: a cross-sectional study in Italy on Multiple Sclerosis. Eur J Public Health. 2015;25(5):775-780. doi:10.1093/eurpub/ckv065

16. Mak AK, Mackenzie A, Lui MH. Changing needs of Chinese family caregivers of stroke survivors. J Clin Nurs. 2007;16(5):971-979. doi:10.1111/jen.2007.16.issue-5

17. Garvey G, Beesley VL, Janda M, et al. Psychometric properties of an Australian supportive care needs assessment tool for Indigenous patients with cancer. Cancer. 2015;121(17):3018-3026. doi:10.10 02/cncr. 29433

18. Hodgkinson K, Butow P, Hunt GE, et al. The development and evaluation of a measure to assess cancer survivors' unmet supportive care needs: the CaSUN (Cancer Survivors' Unmet Needs measure). Psychooncology. 2007;16(9):796-804. doi:10.1002/(ISSN)1099-1611

19. Schulz KH, Kroencke S, Ewers H, Schulz H, Younossi ZM. The factorial structure of the Chronic Liver Disease Questionnaire (CLDQ). Qual Life Res. 2008;17(4):575-584. doi:10.1186/s12955016-0482-y

20. Zhang Y, Yang Y, Lv J, Zhang Y. LC-PROM: validation of a patient reported outcomes measure for liver cirrhosis patients. Health Qual Life Outcomes. 2016;14:75.
21. Highet G, Crawford D, Murray SA, Boyd K. Development and evaluation of the Supportive and Palliative Care Indicators Tool (SPICT): a mixed-methods study. BMJ Support Palliat Care. 2014;4(3):285-290.

22. Powell EE, Skoien R, Rahman T, et al. Increasing hospitalization rates for cirrhosis: overrepresentation of disadvantaged Australians. EClinicalMedicine. 2019;11:44-53. doi:10.1016/j.eclinm.2019.05. 007

23. Australian Institute of Health and Welfare (AIHW). Rural, Regional and Remote Health: A Guide to Remoteness Classifications. Canberra, Australia: AIHW; 2004.

24. Australian Bureau of Statistics (ABS). Census of Population and Housing: Socio-Economic Indexes for Areas (SEIFA), Australia, 2006. Canberra, Australia: ABS; 2008.

25. Ware JE Jr, Sherbourne CD, The MOS. 36-item short-form health survey (SF-36). I. Conceptual framework and item selection. Med Care. 1992;30(6):473-483. doi:10.1097/00005650-199206000-00002

26. National Comprehensive Cancer Network. NCCN clinical practice guidelines in oncology (NCCN guidelines) - distress management version 3.2015:NCCN.org. 2015. Available from: https://www.nccn. org/professionals/physician_gls/pdf/distress.pdf. Accessed November 20, 2017.

27. Terwee CB, Bot SD, de Boer MR, et al. Quality criteria were proposed for measurement properties of health status questionnaires. J Clin Epidemiol. 2007;60(1):34-42. doi:10.1016/j. jclinepi.2006.03.012

28. Hays RD, Anderson R, Revicki D. Psychometric considerations in evaluating health-related quality of life measures. Qual Life Res. 1993;2(6):441-449. doi:10.1007/BF00422218

29. Cohen J. A coefficient of agreement for nominal scales. Educ Psychol Meas. 1960;20:37-46. doi:10.1177/001316446002000104

30. O'leary S, Lund M, Ytre-hauge TJ, et al. Pitfalls in the use of kappa when interpreting agreement between multiple raters in reliability studies. Physiotherapy. 2014;100(1):27-35. doi:10.1016/j. physio.2013.08.002

31. Janani $\mathrm{K}$, Jain $\mathrm{M}$, Vargese $\mathrm{J}$, et al. Health-related quality of life in liver cirrhosis patients using SF-36 and CLDQ questionnaires. Clin Exp Hepatol. 2018;4(4):232-239. doi:10.5114/ceh.2018.80124

32. Khairullah S, Mahadeva S. Translation, adaptation and validation of two versions of the Chronic Liver Disease Questionnaire in Malaysian patients for speakers of both English and Malay languages: a cross-sectional study. BMJ Open. 2017;7(5):e013873. doi:10.1136/bmjopen-2016-013873

33. Moses N, Wiggers J, Nicholas C, Cockburn J. Development and psychometric analysis of the systemic lupus erythematosus needs questionnaire (SLENQ). Qual Life Res. 2007;16(3):461-466. doi:10.1007/s11136-006-9137-5

34. DeVellis RF. Scale Development: Theory and Applications. Thousand Oaks (CA): Sage Publications; 2016.

35. El-atem N, Irvine KM, Valery PC, et al. Identifying areas of need relative to liver disease: geographic clustering within a health service district. Aust Health Rev. 2017;41(4):407-418. doi:10.1071/AH15225

36. The Kirby Institute. HIV, Viral Hepatitis and Sexually Transmissible Infections in Australia: Annual Surveillance Report 2016. Sydney: The Kirby Institute, UNSW Australia; 2016.

37. Clark PJ, Stuart KA, Leggett BA, et al. Remoteness, race and social disadvantage: disparities in hepatocellular carcinoma incidence and survival in Queensland, Australia. Liver Int. 2015;35(12):2584-2594. doi:10.1111/liv.12853

38. Mann AG, Trotter CL, Balogun MA, Ramsay ME. Hepatitis C in ethnic minority populations in England. J Viral Hepat. 2008;15 (6):421-426.

39. Moadel AB, Morgan C, Dutcher J. Psychosocial needs assessment among an underserved, ethnically diverse cancer patient population. Cancer. 2007;109(2 Suppl):446-454. doi:10.1002/cncr.22357 


\section{Publish your work in this journal}

Patient Preference and Adherence is an international, peer-reviewed, open access journal that focuses on the growing importance of patient preference and adherence throughout the therapeutic continuum. Patient satisfaction, acceptability, quality of life, compliance, persistence and their role in developing new therapeutic modalities and compounds to optimize clinical outcomes for existing disease states are major areas of interest for the journal. This journal has been accepted for indexing on PubMed Central. The manuscript management system is completely online and includes a very quick and fair peer-review system, which is all easy to use. Visit http:// www.dovepress.com/testimonials.php to read real quotes from published authors. 